\title{
Beberapa Sifat Kimia Tanah pada Berbagai Jenis Tanaman Penutup Tanah di Perkebunan Karet
}

\section{(Selected Soil Chemical Properties under Various Species of Land Cover Crop in Rubber Plantation)}

\author{
Zainal Muktamar ${ }^{1}$, P. Prawito ${ }^{1}$, dan T. Nugroho ${ }^{2}$ \\ 1) Dosen Fakultas Pertanian UNIB \\ 2) Alumni Fakultas Pertanian UNIB
}

\begin{abstract}
Land cover crop has been widely utilized in big rubber plantation to improve soil fertility and productivity. The objective of the experiment were to determine selected soil chemical properties on various species of land cover crop in rubber plantation and to find out land cover crop potential for rubber plantation. The experiment was conducted in PTP Nusantara VII Rubber Plantation in Padang Pelawi, Seluma, Province of Bengkulu. Soil samples were collected using simple random sampling on land cover crops Calopogonium mucunoides in old rubber plant (CC), Panicum muticum in old rubber plant (PT), Panicum muticum in young rubber plant (PD), Pueraria javanica in young rubber plant (PJ), Wedelia triobata in young rubber plant (W), and mixture of Panicum muticum and Mikania microtha in young rubber plant, and control $(\mathrm{K})$. The size of each treatment plot was $5 \times 15 \mathrm{~m}$, divided into small plot $(3 \times 5$ $\mathrm{m})$ as replication. Soil sample was collected from each small plot at depths of $0-20 \mathrm{~cm}$, and 20$50 \mathrm{~cm}$. The experiment revealed that land cover crops significantly increased total soil nitrogen, available $\mathrm{P}$, and total potassium in soil. Panicum muticum in young rubber plant enhanced total soil nitrogen at top soil $(0-20 \mathrm{~cm}) 10$ higher than that of control. At the same depth, Calopogonium mucunoides in old rubber plant increased available $\mathrm{P}$ and soil organic carbon as much as $520 \%$ and $210 \%$, as compared to those of control, respectively. Panicum muticum and Calopogonium mucunoides tended to have better influence on soil chemical properties as compared to Pueraria javanica and Wedelia trilobata.
\end{abstract}

Keywords: Land cover crop, rubber,

PENDAHULUAN

Sebagai salah satu komoditas perkebunan andalan, karet memiliki peran penting sebagai bahan ekspor non-migas. Berbagai cara telah dilakukan untuk meningkatkan produksi karet melalui perluasan areal, intensifikasi maupun rehabilitasi disertai dengan penggunaan teknologi. Pada tahun 2009, luas areal tanaman karet pada perkebunan besar mencapai 516.400 ha dengan produksi karet kering sebesar 640.787 ton. Selama sepuluh tahun terakhir produksi karet kering meningkatkat cukup signifikan walaupun luas tanamnya relatif tidak berubah (BPS, 2011).

Pada perkebunan besar, pertanaman karet seringkali ditanami penutup tanah. Menurut Nazarudin dan Paimin (1999) terdapat tiga golongan tanaman penutup tanah yaitu tanaman penutup tanah rendah (rumput dan legume), semak, dan pohon. Beberapa jenis tanaman penutup tanah yang sering digunakan pada perkebunan karet diantaranya Psophocurphus palutris, Pueraria javanica, Colopogonium mucunoides, dam Centrosema pubescens yang seringkali disebut dengan Land Cover Crop (LCC) (Sukman dan Yakub, 2000), disamping jenis tanaman penutup tanah lainnya. Tanaman penutup tanah pada perkebunan karet dapat melindungi tanah terhadap erosi, mengurangi penguapan air pada permukaan tanah, membantu menyimpan air dalam tanah, meningkatkan unsur hara melalui pelapukan bahan organik (Setyamijaya, 1993). 
Perbaikan ekosistem tanah ini akan mempengaruhi sifat fisik, kimia, biologi maupun mikrobiologi tanah. Hasil peneltian Sehan (2005) menunjukkan bahwa tanaman Wedelia meyumbangkan $\mathrm{N}$ tersedia kedalam tanah dalam jumlah yang lebih tinggi daripada Chromolaena dan Melastoma. Hasil penelitian lain yang dilakukan oleh Syerni (2005) menunjukkan bahwa Chromolaena meningkatkan kadar $\mathrm{C}$ dalam tanah. Penggunaan rumputrumputan sebagai tanaman penutup tanah dapat mengurangi terjadinya erosi, selain untuk pakan ternak (Rahman et al., 1996)

Penelitian ini bertujuan untuk menentukan beberapa sifat kimia tanah pada berbagai jenis tanaman penutup tanah perkebunan karet, membandingkan beberapa sifat kimia tanah pada berbagai jenis tanaman penutup tanah, dan mendapatkan jenis tanaman penutup tanah yang paling baik untuk digunakan pada perkebunan karet.

\section{METODOLOGI PENELITIAN}

\section{Perlakuan dan Pengambilan Sampel Tanah}

Peneltian ini dilaksanakan di Perkebunan Karet PTP Nusantara VII Padang Pelawi, Sukaraja, Kabupaten Seluma, Provinsi Bengkulu. Luas areal perkebunan tersebut sebesar 4357 ha, yang terdiri dari plasma dan PIR. Ketinggian lokasi penelitian sekitar $200 \mathrm{~m}$ dpl.

Sampel tanah diambil dengan menggunakan Simple Random Sampling pada berbagai jenis tanaman penutup tanah yaitu Calopogonium mucunoides di lorong karet tua (CC), Panicum muticum di lorong karet tua (PT), Panicum muticum di lorong karet muda (PD), Pueraria javanica di lorong karet muda (JP), Wedelia trilobata di lorong karet muda (W), dan canpuran Panicum muticum dan Mikania microtha di lorong karet muda (PM) serta kontro atau tanpa tanaman penutup tanah (K). Petak pengambilan sampel tanah berukuran $5 \times 15 \mathrm{~m}$. Setiap petakan dibuat 3 petakan kecil dengan ukuran $5 \times 3 \mathrm{~m}$ sebagai ulangan, sehingga jumlah petak ulangan 21 petak.

Sampel tanah diambil dari setiap petak ulangan pada kedalaman 0-20 cm (lapisan 1) dan 20-50 cm (lapisan 2) pada 5 titik secara acak. Sampel tanah kemudian dikomposit, dikeringanginkan dan disaring dengan ayakan ukuran $0,5 \mathrm{~mm}$. Sampel tanah kemudian dianalisis di Laboratorium Ilmu Tanah Fakultas Pertanian Univesitas Bengkulu sesuai dengan variabel yang diamati.

\section{Variabel dan Analisis Data}

Variabel karakteristik kimia tanah yang diamati pada penelitian ini meliputi kadar Ntotal tanah, yang dianalisis dengan menggunakan metode Micro Kjeldahl, P-tersedia tanah yang dianalisis dengan metode Bray-Kurtz, K-total tanah yang dianalisis dengan metode Gravimetrik dan Titrasi, C-organik tanah dengan metode Kurmies serta $\mathrm{pH}$ tanah dengan metode elektrometrik pada perbandingan tanah dan air 1:1. Data pengamatan yang diperoleh kemudian dianalisis dengan sidik ragam pada taraf 5\%. APabila terdapat perlakuan yang berbeda nyata, kemudian diuji lanjut dengan DMRT pada taraf 5\%.

\section{HASIL DAN PEMBAHASAN}

\section{Keadaan Umum Lokasi Penelitan}

Lokasi penelitian terletak di PTP Nusantara VII pada lahan yang memiliki jenis tanah Ultisol. Jenis tanah ini memiliki tekstur liat berpasir, $\mathrm{pH}$ berkisar antara 3,5-5,0. Iklim lokasi penelitia termasuk tupe A (sangat basah) menurut kategori Schmidt dan Ferguson dengan ratarata curah hujan bulanan lebih dari $300 \mathrm{~mm}$. Tanaman karet yang diusahakan bervariasi mulai tanaman yang masih muda sampai tanaman tua yang berumur antara 20-25 tahun. Tanaman karet yang tua telah mulai dilakukan peremajaan. 


\section{Karakteristik Kimia Tanah pada Tanaman Penutup Tanah}

Secara umum, tanaman penutup tanah mampu meningkatkan secara nyata N-total tanah, P-tersedia, dan K-total tanah dibandingkan dengan control, tetapi tidak memberikan perbedaan yang berarti terhadap C-organik dan $\mathrm{pH}$ tanah. Penggunaan Panicum muticum dan Calopogonium mucunoides meningkatkan kadar N-total tanah pada lapisan 0-20 cm lebih tinggi daripada jenis tanaman penutup tanah yang lain seperti terlihat pada Tabel 1.

Tabel 1. Beberapa sifat kimia tanah lapisan 0-20 $\mathrm{cm}$ pada lahan perkebunan karet yang ditanami beberapa jenis tanaman penutup tanah

\begin{tabular}{cccccc}
\hline Jenis tanaman & N Total (\%) & $\begin{array}{c}\text { P-tersedia } \\
(\mathbf{p p m})\end{array}$ & $\mathbf{K}(\mathbf{p p m})$ & $\mathbf{C - o r g}(\mathbf{\%})$ & $\mathbf{p H}$ \\
\hline CC & $0.18 \mathrm{ab}$ & $4.22 \mathrm{c}$ & $0.80 \mathrm{ab}$ & 1.50 & 4.03 \\
PT & $0.12 \mathrm{bc}$ & $2.49 \mathrm{~b}$ & $0.28 \mathrm{~b}$ & 1.12 & 4.67 \\
PD & $0.20 \mathrm{a}$ & $0.78 \mathrm{a}$ & $0.53 \mathrm{~b}$ & 1.34 & 4.47 \\
W & $0.08 \mathrm{c}$ & $1.21 \mathrm{~b}$ & $0.46 \mathrm{~b}$ & 1.31 & 4.37 \\
PM & $0.11 \mathrm{c}$ & $2.12 \mathrm{~b}$ & $0.58 \mathrm{ab}$ & 0.92 & 4.67 \\
PJ & $0.04 \mathrm{~d}$ & $2.40 \mathrm{~b}$ & $1.33 \mathrm{a}$ & 1.15 & 4.53 \\
K & $0.02 \mathrm{~d}$ & $0.8 \mathrm{a}$ & $0.75 \mathrm{~b}$ & 0.71 & 4.57 \\
\hline
\end{tabular}

Keterangan: $\mathrm{CC}=$ Calopogonium mucunoides, $\mathrm{PT}=$ Panicum muticum karet tua, $\mathrm{PD}=$ Panicum muticum karet muda, $\mathrm{W}=$ Wedelia, $\mathrm{PM}=$ Panicum muticum + Mikania, $\mathrm{PJ}=$ Pueraria javanica, dan $\mathrm{K}=$ Kontrol

Nilai yang diikuti huruf sama tidak berbeda nyata pada uji DMRT taraf 5\%

Tabel 1 menunjukkan bahwa pada tanah lapisan 0-20 cm, perlakuan Panicum muticum pada lorong karet muda mampu meningkatkan N-total tanah sebesar 10 kali lipat dibandingkan kontrol, sedangkan perlakuan Pueraria javanica hanya meningkatkan 2 kali lipat lebih tinggi daripada kontrol. Pada perlakuan yang lain peningkatan $\mathrm{N}$ total tanahnya berada diantara kedua perlakuan tersebut. Peningkatan kadar N-total tanah ini berkaitan dengan peningkatan bahan organik tanah yang kemudian mengalami pelapukan. Tanaman penutup tanah juga meningkatkan kadar N-total tanah lapisan $20-50 \mathrm{~cm}$, walaupun nilainya lebih rendah daripada lapisan 0-20 cm (Tabel 2).

Tabel 2. Beberapa sifat kimia tanah lapisan $20-50 \mathrm{~cm}$ pada lahan perkebunan karet yang ditanami beberapa jenis tanaman penutup tanah

\begin{tabular}{cccccc}
\hline Jenis tanaman & N Total (\%) & $\begin{array}{c}\text { P-tersedia } \\
\text { (ppm) }\end{array}$ & $\mathbf{K}(\mathbf{p p m})$ & $\mathbf{C - o r g}(\mathbf{\%})$ & $\mathbf{p H}$ \\
\hline CC & $0.09 \mathrm{~b}$ & 0.40 & 0.53 & 0.55 & 4.33 \\
PT & $0.08 \mathrm{~b}$ & 0.74 & 0.18 & 0.44 & 4.63 \\
PD & $0.15 \mathrm{a}$ & 0.61 & 0.50 & 0.66 & 4.43 \\
W & $0.12 \mathrm{a}$ & 0.91 & 0.80 & 0.34 & 4.50 \\
PM & $0.04 \mathrm{c}$ & 1.18 & 0.58 & 0.37 & 4.37 \\
PJ & $0.03 \mathrm{c}$ & 0.58 & 0.75 & 0.30 & 4.63 \\
K & $0,01 \mathrm{c}$ & 0.46 & 0.31 & 0.20 & 4.40 \\
\hline
\end{tabular}

Keterangan: $\mathrm{CC}=$ Calopogonium mucunoides, $\mathrm{PT}=$ Panicum muticum karet tua, $\mathrm{PD}=$ Panicum muticum karet muda, $\mathrm{W}=$ Wedelia, $\mathrm{PM}=$ Panicum muticum + Mikania, $\mathrm{PJ}=$ Pueraria javanica, dan $\mathrm{K}=$ Kontrol

Nilai yang diikuti huruf sama tidak berbeda nyata pada uji DMRT taraf 5\%

Tabel 2 menunjukkan bahwa perlakuan Panicum muticum mampu meningkatkan N-total tanah sebesar 15 kali lipat dibandingkan control, sedangkan Pueraria javanica meningkatkan Ntotal tanah sebesar 3 kali lipat dibandingkan control. Seperti halnya pada lapisan 0-20 cm, perlakuan jenis tanaman penutup tanah lainnya meningkatkan $\mathrm{N}$-total tanah pada kisaran antara kedua perlakuan tersebut.

Peningkatan $\mathrm{N}$-total tanah pada lapisan ini mengindikasikan terjadinya pencucian $\mathrm{N}$ dari lapisan atas ke lapisan dibawahnya. Pencucian $\mathrm{N}$ dapat berupa $\mathrm{N}$-anorganik yaitu hasil 
dekomposisi bahan organik pada lapisan pertama dan atau N-organik yaitu pencucian bahan organik dari lapisan atas.

Selain N, penggunaan tanaman penutup tanah diantara tanaman karet secara nyata meningkatkan P-tersedia tanah seperti terlihat pada Tabel 1 dan Tabel 2. Tabel 1 menunjukkan bahwa penggunaan Calopogonium mucunoides menaikkan kadar P-tersedia tanah lebih dari $400 \%$ dibandingkan kontrol. Tanaman penutup tanah lainnya dapat menaikkan kadar P-tersedia lebih kecil dibandingkan Calopogonium mucunoides. Hal ini mengindikasikan bahwa pelapukan Calopogonium mucunoides dapat menyumbangkan $\mathrm{P}$ kedalam tanah lebih baik daripada tanaman penutup tanah lainnya.

Pada lapisan 20-50 cm, tanaman penutup tanah tidak memberikan peningkatan P-tersedia tanah yang berarti. Hal ini menunjukkan bahwa P tidak tercuci dari lapisan 1 ke lapisan 2. Hal ini terkait dengan reaksi $\mathrm{P}$ dengan senyawa lain pada lapisan pertama. Unsur $\mathrm{P}$ cenderung bereaksi dengan senyawa AL, Fe, maupun Ca membentuk senyawa kompleks Al-P, Fe-P, maupun Ca-P sehingga $\mathrm{P}$ tidak tersedia bagi tanaman seperti dilaporkan oleh Pujiyanto et al. (2004).

Penggunaan tanaman penutup tanah secara nyata dapat meningkatkan K-total tanah pada lapisan 0-20 cm (Tabel 1). Kadar K-total tanah pada lorong tanaman karet yang ditanami Pueraria javanica meningkat sampai $180 \%$ dibandingkan kontrol, sedangkan penggunaan tanaman penutup lainnya tidak memberikan pengaruh yang berarti. Hal ini menunjukkan bahwa pelapukan seresah Pueraria javanica menyumbangkan K kedalam tanah lebih baik daripada tenaman penutup tanah lainnya.

Pada lapisan tanah 20-50 cm, penggunaan tanaman penutup tanah tidak memberikan pengaruh yang berarti terhadap $\mathrm{K}$ total tanah. Hal ini mengindikasikan bahwa walaupun terdapat peningkatan K total tanah pada lapisan 0-20 cm seperti penggunaan Pueraria javanica, K tidak mengalami pencucian dari lapisan 1 ke lapisan 2.

Tabel 1 dan 2 juga menunjukkan bahwa tanaman penutup tanah belum mampu meningkatkan kadar C-organik tanah secara sgnifikan baik pada lapisan 0-20 cm maupun lapisan 20-50 $\mathrm{cm}$. Pelapukan bahan organik, selain melepaskan asam-asam organik dan unsur hara kedalam tanah, juga melepaskan $\mathrm{CO}_{2}$ ke udara, sehingga $\mathrm{C}$-organik dalam tanah belum meningkat secara signifikan. Walaupun demikian, Tabel 1 menunjukkan bahwa C-organik tanah cenderung meningkat dengan perlakuan Calopogonium mucunoides dan Panicum muticum pada lorong tanaman karet muda yaitu masing $210 \%$ dan $89 \%$ dibandingkan kontrol.

Tabel 2 menunjukkan bahwa pada lapisan $20-50 \mathrm{~cm}$, perlakuan Calopogonium mucunoides dan Panicum muticum juga cenderung meningkatkan C-organik tanah, dengan peningkatan masing-masing 1.75 dan 4.4 lipat dibanding kontrol. Kedua tanaman penutup tanah ini memiliki potensi untuk meningkatkan C-organik tanah.

Hasil penelitian ini juga menunjukkan bahwa tanaman penutup tanah tidak memberikan pengaruh yang berarti terhadap $\mathrm{pH}$ tanah (Tabel 1 dan 2). Hasil penelitian terdahulu yang dilakukan oleh Sehan (2005) juga menyatakan bahwa tanaman pioneer tidak memberikan pengaruh terhadap $\mathrm{pH}$ tanah.

Hasil penelitian ini juga menunjukkan bahwa setiap jenis tanaman penutup tanah memberikan pengaruh yang relative berbeda terhadap unsur hara dalam tanah. Perlakuan Panicum muticum meningkatkan N-total tanah lebih baik daripada jenis penutup tanah lainnya, sedangkan penggunaan Calopogonium mucunoides memberikan kontribusi peningkatan $\mathrm{P}$ dan $\mathrm{C}$ lebih baik daripada jenis tanaman penutup tanah lainnya. Penggunaan Pueraria javanica dan Wedelia trilobata dapat meningkatkan kadar K-total tanah lebih baik dibandingkan jenis tanaman penutup tanah lainnya. Namun demikian, secara keseluruhan pada Tabel 1 dan 2 dapat dilihat bahwa Calopogonium mucunoides dan Panicum muticum cenderung memiliki potensi lebih baik dalam memberikan kontribusi perbaikan beberapa sifat kimia tanah.

\section{KESIMPULAN}

1. Penggunaan tanaman penutup tanah pada perkebunan karet dapat meningkatkan N-total, Ptersedia, K-total tanah dan cenderung meningkatkan C-organik tanah, tetapi tidak memberikan pengaruh terhadap $\mathrm{pH}$ tanah

2. Jenis tanaman Panicum muticum pada lorong tanaman karet muda mampu meningkatkan Ntotal lapisan tanah 0-20 cm sebesar 10 kali lipat dibandingkan kontrol. Penggunaan Calopogonium mucunoides mampu meningkatkan kadar P-tersedia tanah dan cenderung 
meningkatkan C-organik tanah lapisan 0-20 cm masing masing sebesar $420 \%$ dan $210 \%$ dibandingkan kontrol.

3. Jenis tanaman penutup tanah Panicum muticum dan Calopogonium mucunoides cenderung memiliki potensi lebih baik dalam memperbaiki sifat kimia tanah dibandingkan Pueraria javanica dan Wedelia trilobata

\section{DAFTAR PUSTAKA}

Badan Pusat Statistik. 2011. Luas tanaman perkebunan besar menurut jenis tanaman 1995-2009. http//www.bps.go.id/aboutus.php?tabel=1@id_subyek=54, 27 April 2011.

Nazaruddin dan B. Paimin. 1999. Karet, Strategi Pemasaran Tahun 2000, Budidaya dan Pengolahannya.Penebar Swadaya. Jakarta

Pujiyanto, S., A. Rahim, S. Sabiham, A. Sastiono, dan J.B. Baon. 2004. Pengaruh bahan organik dan jenis tanaman penutup tanah terhadap bentuk-bentuk $\mathrm{P}$ dalam aggregate tanah. Jurnal Tanah Tropika. 18:117-126

Rahman, A. Sy., E. Handalia, Roslinda, dan H. Syarifuddin. 1996. Nilai gizi beberapa jenis rumput makanan ternak yang bterdapat secara alami di kota Jambi. Jurnal Ilmu-Ilmu Pertanian. 4(1):49-54

Sehan, N. 2005. Pengaruh budidaya tumbuhan pioneer dan pupuk organik terhadapkesuburan tanah lahan alang-alang. Skripsi Fakultas Pertanian Universitas Bengkulu (tidak dipublikasikan)

Setyamidjaja, D. 1993. Karet: Budidaya dan Pengolahan. Kanisiun, Yogyakarta.

Sukman dan Y. Yakub. 2002. Gulma dann Tehnik Pengendaliannnya (edisi revisi). PT Raja Grafindo Persada. Jakarta.

Syerni, A.D. 2005. Potensi pertumbuhan pioneer dan pupuk organik dalam mereklamasi lahan bekas alang-alang. Skripsi Fakultas Pertanian Universitas Bengkulu (tidak dipublikasikan). 